\title{
STUDIES ON STEEL STRIP'S HEAT TRANSFER BEHAVIOUR FEEDING INTO CONTINUOUS CASTING MOULD BASED ON PROCAST
}

\section{LINHUI YU ${ }^{1}$, ZHENSHAN ZHANG ${ }^{1,2}$, SHEVCHENKO ANTHONY ${ }^{3}$, MINGGANG SHEN ${ }^{1}$ and DONGYE LIU ${ }^{1}$}

1Yingkou Metallurgical Equipment

and Refractory's Company Limited

Technology Center

Yingkou 115100, Liaoning

P. R. China

e-mail: lnaszzs@163.com

2Applied Technology School

University of Science and Technology Liaoning

Anshan 114051, Liaoning

P. R. China

${ }^{3}$ Ferrous Metallurgy Research Institute of NAS of Ukraine

Dnipropetrovsk 49125

Ukraine

\begin{abstract}
Center segregation and equiaxial crystal ratio are the important parameters to evaluate the quality of continuous casting slab. And the technologies of improving internal quality. In this paper, a continuous casting model is established, and the heat transfer law of steel strip in continuous casting mould is obtained by the finite element analysis software ProCAST.
\end{abstract}

Keywords and phrases: continuous casting, feeding steel strip, heat transfer.

Received August 31, 2016

(C) 2016 Scientific Advances Publishers 


\section{Introduction}

Because of the high production efficiency, low cost and good quality, the continuous casting technology has an absolute proportion in the steel production [1-3]. Therefore, the quality of continuous casting billet restricts the final product quality and economic benefit of steel enterprises directly. The quality problem of continuous casting billet is the segregation, porosity and crack of continuous casting slab mainly. To improve the internal quality, one of the ways is to improve the solidification process and increase the equal axial grain rate $[5,6]$. The methods of improving the equal axial grain rate include the electromagnetic stirring, the light reduction and the micro alloying, but the methods are more complicated and the cost is high relatively. In the mould, the steel strip is inserted into the liquid steel, and the heat of the surrounding liquid steel is reduced through melting and heat absorbing of the steel strip.

Due to the melting of the steel strip, a large number of solidified crystal nuclei are produced. Through the functions, the equal axial grain rate can be improved effectively, so that the center of the continuous casting slab is compact and the composition is uniform, preventing or reducing the generation of the central defect. The technique has the advantages of simple equipment, convenient operation, low construction cost and good effect. And it has positive effect on the improvement of the quality of the continuous casting slab. In the present study, the numerical simulation and the hot state test are mostly used in the research of the mould strip insert technique. In this paper, the heat transfer behaviour of the steel strip in continuous casting mould is analyzed. 


\section{Principles in the Modal}

In this paper, the model is calculated and analyzed by using the method of $2 \mathrm{D}$ section travelling. Due to lateral (the wide and narrow faces of casting billet) heat transfer was much higher than that of the casting direction, the heat transfer of the casting direction is ignored. Molten steel flow is set as incompressible flow. The thermal conductivity is isotropic. The thermal physical properties of steel are only related to temperature. Considering the influence of continuous casting of molten steel flow on heat transfer, set the thermal conductivity of liquid steel as 5 times for absolute thermal conductivity [7].

The heat transfer control equation is used in the calculation as following:

$$
\rho c \frac{\partial T}{\partial t}=\frac{\partial}{\partial x}\left(\lambda \frac{\partial T}{\partial x}\right)+\frac{\partial}{\partial y}\left(\lambda \frac{\partial T}{\partial y}\right)
$$

In the equation:

$T$-temperature, ${ }^{\circ} \mathrm{C}$;

$\rho$-liquid steel density, $\mathrm{kg} / \mathrm{m}^{3}$;

$\lambda$-thermal conductivity, $\mathrm{W} /\left(\mathrm{m}_{*}{ }^{\circ} \mathrm{C}\right)$;

$c$-Specific heat, $\mathrm{J} /\left(\mathrm{kg}_{*} \mathrm{~K}\right)^{0}$.

\section{Structure of the Modal}

In the simulation, the continuous casting billet section is $1400 \mathrm{~mm} \times$ $200 \mathrm{~mm}$, and the steel strip section is $100 \mathrm{~mm} \times 3 \mathrm{~mm}$. The position of insertion is parallel to the narrow face and $350 \mathrm{~mm}$ to the left. The model of the slab is shown in Figure 1. 


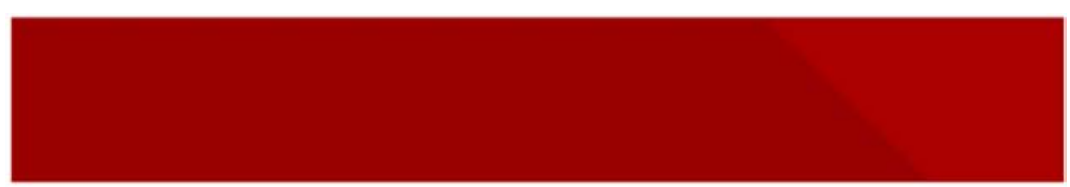

(a)Without strip

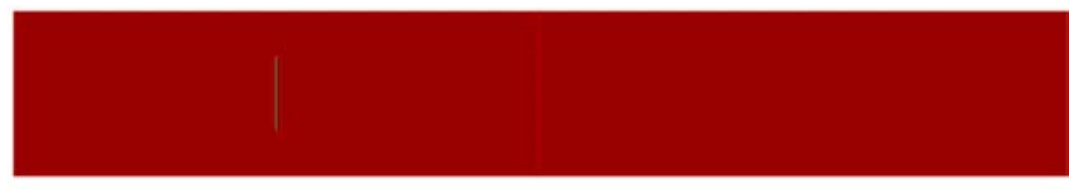

(b)With strip

Figure 1. Sketch map of slab model.

The mesh of the model is shown in Figure 2.

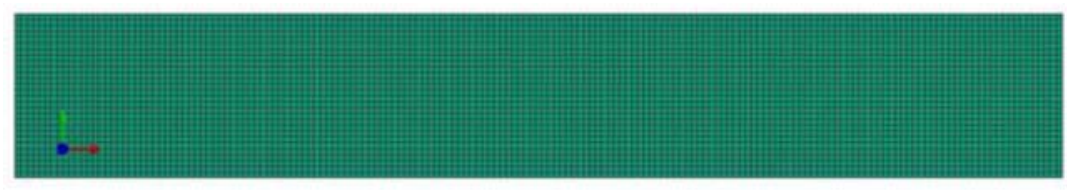

(a)Without strip

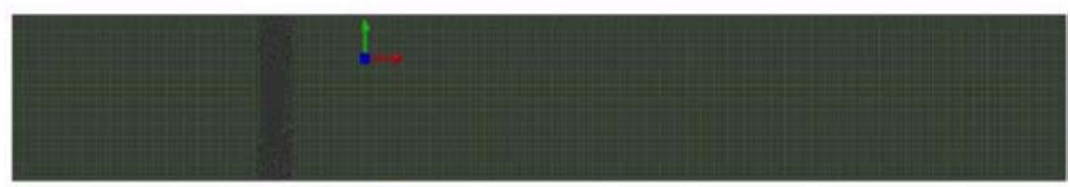

(b)With strip

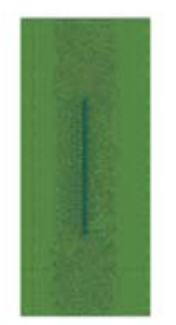

(c) Local mesh encryption

Figure 2. Mesh of model. 
In this paper, the pouring temperature of molten steel is $1540^{\circ} \mathrm{C}$, and the initial temperature of the steel strip is $100^{\circ} \mathrm{C}$.

\section{Analysis of the Results}

Generally, the steel strip is thickened at first and then melting gradually (Figure 3). The faster the insertion speed is, the larger thickening of the strip thickness is with the insertion speed $3.6 \mathrm{~m} / \mathrm{min}$, the thickness reaches the maximum of $4 \mathrm{~mm}$ in $2.69 \mathrm{~s}$ with the insertion speed $6 \mathrm{~m} / \mathrm{min}$, the thickness reaches the maximum of $7.7 \mathrm{~mm}$ in $7.4 \mathrm{~s}$ with the insertion speed $12 \mathrm{~m} / \mathrm{min}$, the thickness reaches the maximum of $15.9 \mathrm{~mm}$ in $16.5 \mathrm{~s}$. This is because the faster the insertion speed is, the larger quality the cold steel strip is accumulated in the molten steel, and the cooling effect is stronger (Figures 3-7).

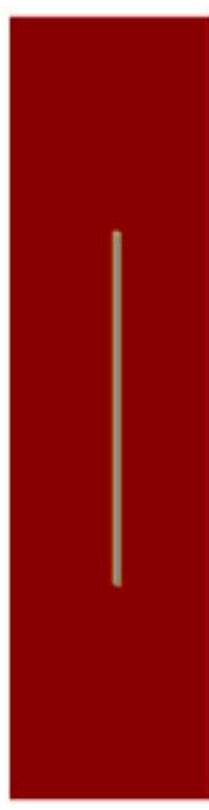

0s

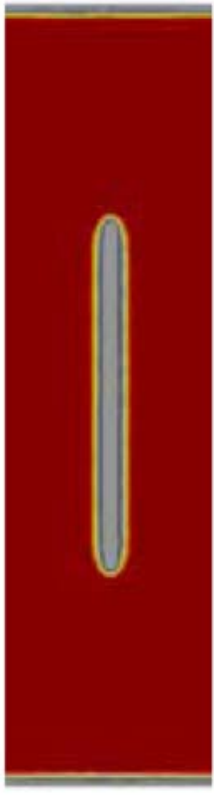

$2.29 \mathrm{~s}$

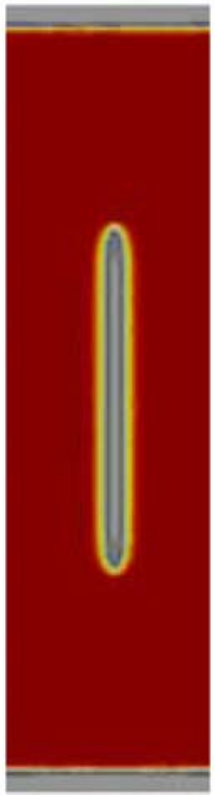

$5.69 \mathrm{~s}$

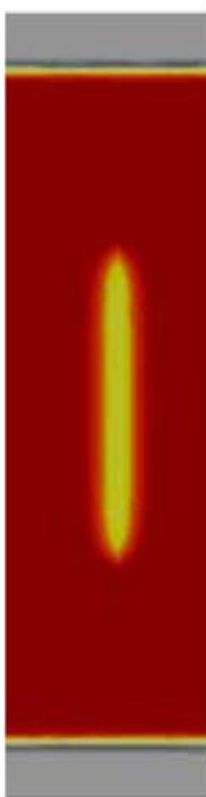

20.69 s

Figure 3. Solid phase rate of steel strip (with insertion speed $3.6 \mathrm{~m} / \mathrm{min}$ ). 


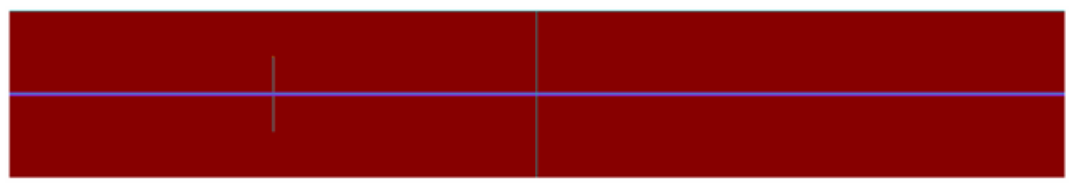

Figure 4. Data node selection range (the horizontal line).

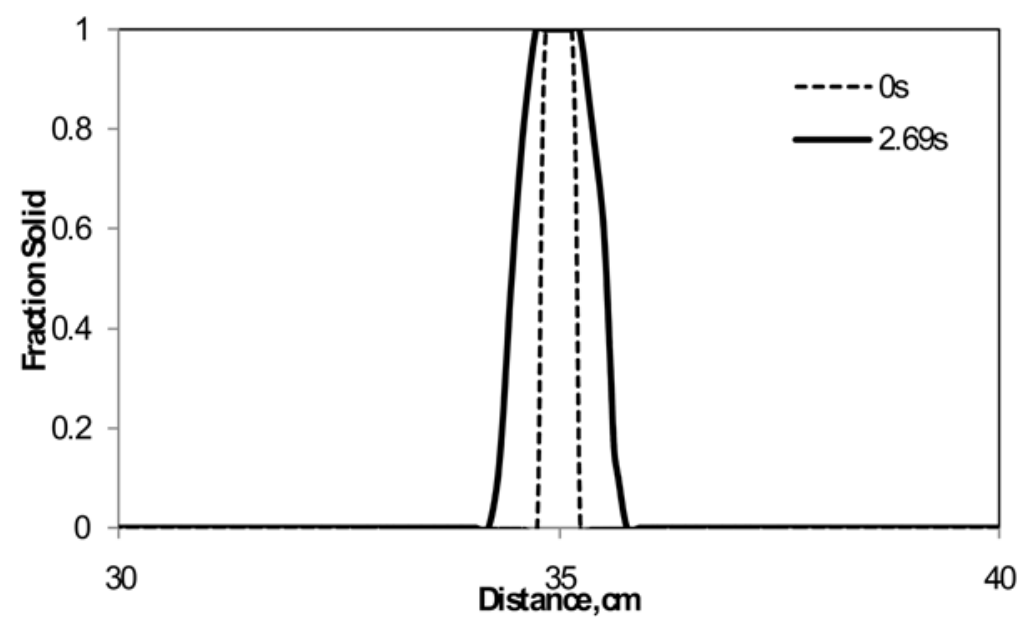

Figure 5. The change of solid phase rate with $3.6 \mathrm{~m} / \mathrm{min}$ steel strip insertion speed.

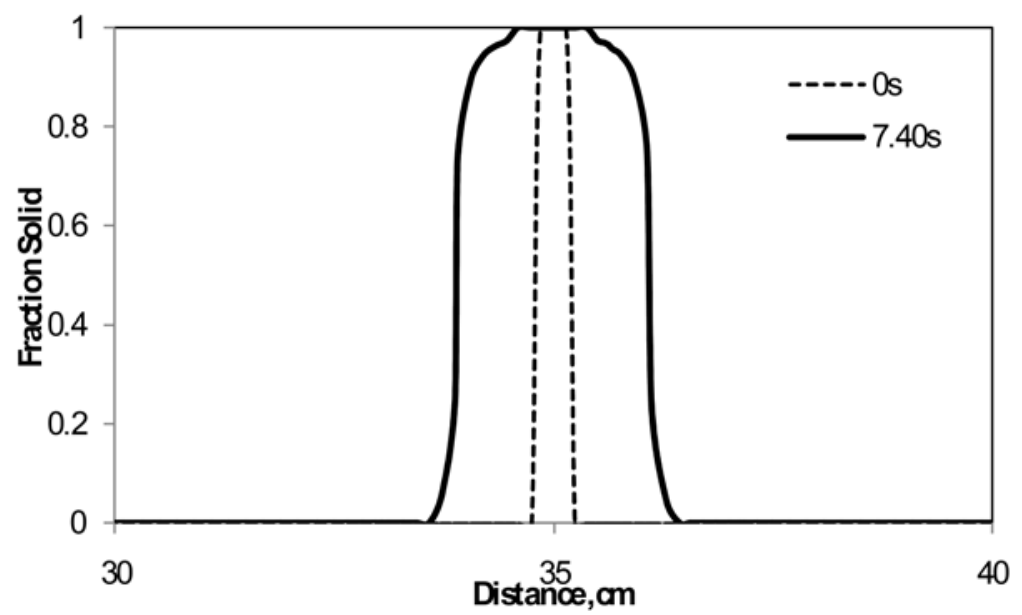

Figure 6. The change of solid phase rate with $6 \mathrm{~m} / \mathrm{min}$ steel strip insertion speed. 


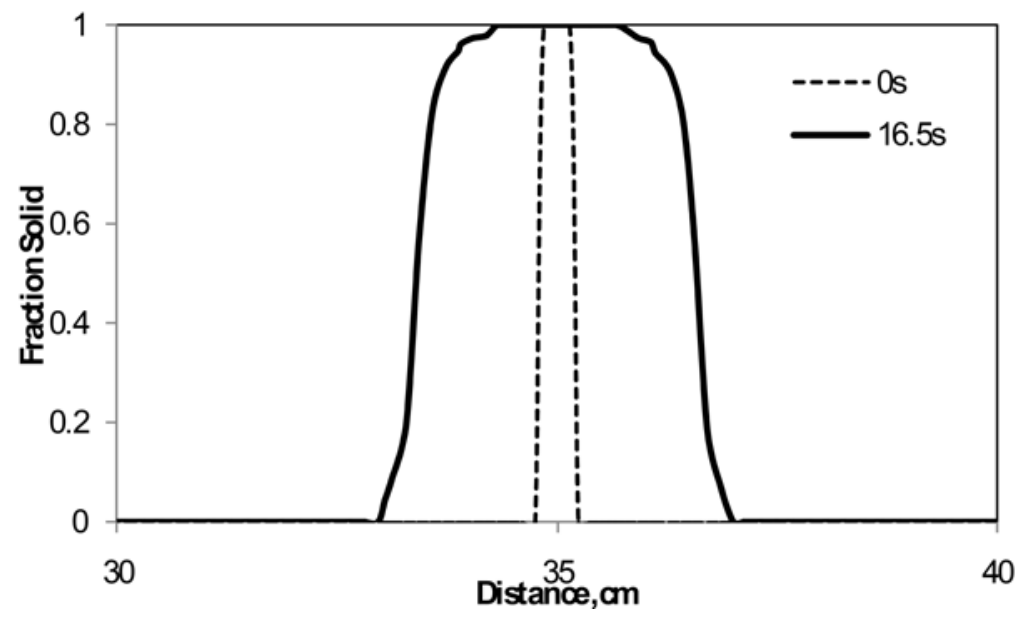

Figure 7. The change of solid phase rate with $12 \mathrm{~m} / \mathrm{min}$ steel strip insertion speed.

\section{Conclusion}

The faster continuous casting steel strip speed is, the better the steel strip cooling effect is, the direct influence scope is bigger.

In practical operation, too large insertion speed will lead to steel strip cannot melt completely in the continuous casting process, which will be detrimental to improving the quality of continuous casting billet.

\section{Acknowledgements}

This project is supported by International $\mathrm{S} \& \mathrm{~T}$ Cooperation Program of China (No. 2013DFR70500) Zhenshan Zhang is corresponding author.

\section{References}

[1] Zhong Gao, Chuan-Ji Han, Jin-Ming Tao et al., Analysis and improvement of the center segregation in continuous casting slab based on QES, Iron and Steel 48(9) (2013), 31.

[2] Lei Cao, Dynamic soft reduction technology of wide heavy slab continuous casting, China Metallurgy 25(1) (2015), 45. 
[3] Chang-Gui Cheng, Fang Che, Jing Shuai et al., Development of centerline segregation control technology for continuous casting strand, Continuous Casting 6 (2009), 39.

[4] Lei Bao, Zhi-Li Han, Yin-Hua Zhang et al., Quality evaluation of high-speed railway rail, China Metallurgy 24(11) (2014), 11.

[5] Yong Chen, Su-Bo Yang and Miao-Yong Zhu, Key technologies of internal quality control for continuously cast high speed rail steel bloom, Iron and Steel 41(12) (2006), 37.

[6] Xian-Hui Zhan, Jing-Hua Mao and Zhan-Wu Yan, Selection and layout of nozzle for ultra-thick slab continuous caster, Iron and Steel 49(5) (2014), 42.

[7] Wei-Biao Li, Fang Wang, Feng-Sheng Qi et al., Mathematical model on steel stripfeeding of mold in continuous casting process, Acta Metallurgica Sinica 43(11) (2007), 1191. 